\title{
Genetics of healthy aging and longevity
}

\author{
Angela R. Brooks-Wilson
}

Received: 21 December 2012/Accepted: 15 July 2013/Published online: 8 August 2013

(C) The Author(s) 2013. This article is published with open access at Springerlink.com

\begin{abstract}
Longevity and healthy aging are among the most complex phenotypes studied to date. The heritability of age at death in adulthood is approximately $25 \%$. Studies of exceptionally long-lived individuals show that heritability is greatest at the oldest ages. Linkage studies of exceptionally long-lived families now support a longevity locus on chromosome 3; other putative longevity loci differ between studies. Candidate gene studies have identified variants at $A P O E$ and $F O X O 3 A$ associated with longevity; other genes show inconsistent results. Genome-wide association scans (GWAS) of centenarians vs. younger controls reveal only $A P O E$ as achieving genome-wide significance (GWS); however, analyses of combinations of SNPs or genes represented among associations that do not reach GWS have identified pathways and signatures that converge upon genes and biological processes related to aging. The impact of these SNPs, which may exert joint effects, may be obscured by gene-environment interactions or inter-ethnic differences. GWAS and whole genome sequencing data both show that the risk alleles defined by GWAS of common complex diseases are, perhaps surprisingly, found in long-lived individuals, who may tolerate them by means of protective genetic factors. Such protective factors may 'buffer' the effects of specific risk alleles. Rare alleles are also likely to contribute to healthy
\end{abstract}

\footnotetext{
A. R. Brooks-Wilson $(\bowtie)$

Canada's Michael Smith Genome Sciences Centre,

BC Cancer Agency, 675 West 10th Avenue,

Vancouver, BC V5Z 1L3, Canada

e-mail: abrooks-wilson@bcgsc.ca
}

\section{A. R. Brooks-Wilson}

Department of Biomedical Physiology and Kinesiology, Simon Fraser University, 8888 University Drive, Burnaby, BC V5A 1S6, Canada aging and longevity. Epigenetics is quickly emerging as a critical aspect of aging and longevity. Centenarians delay age-related methylation changes, and they can pass this methylation preservation ability on to their offspring. Nongenetic factors, particularly lifestyle, clearly affect the development of age-related diseases and affect health and lifespan in the general population. To fully understand the desirable phenotypes of healthy aging and longevity, it will be necessary to examine whole genome data from large numbers of healthy long-lived individuals to look simultaneously at both common and rare alleles, with impeccable control for population stratification and consideration of non-genetic factors such as environment.

\section{Background}

The basis of human longevity and healthy aging, and how to achieve these desirable phenotypes, remain among the principal challenges of biology and medicine. While an understanding of lifestyle and environmental factors will maximize our ability to prevent disease and maximize health in the general population, studying the genetic basis of longevity and healthy aging in exceptional individuals is providing important biological insights. In model organisms it has been possible to demonstrate effects of mutations in genes that can extend lifespan nearly tenfold (Ayyadevara et al. 2008). Studies of inbred lab strains and of natural genetic variants in model organisms including yeast and worms (Tissenbaum and Guarente 2002), flies (Paaby and Schmidt 2009) and mice (Yuan et al. 2011) have clearly implicated many specific genes in the lifespan of these organisms. Our understanding of human lifespan stands in contrast to this, with only one consistently replicable genetic association, APOE, observed to date in 
several genome-wide association scans (GWAS) of longevity-related traits. This may be because healthy aging and longevity are particularly complex traits, involving not only maintenance of long-term function but also absence or reduction of disease and other morbidities. It has been proposed that human lifespan is influenced not only by longevity assurance mechanisms and disease susceptibility loci but also by the environment, gene-environment interactions, and chance (Cournil and Kirkwood 2001). It will be important to understand the effects of environment (lifestyle) and of genetics, as well as how they interact to affect health and lifespan.

The importance of age and aging is underscored by the recognition that all common complex diseases increase with age. Questions remain about whether aging is the cause or effect of such diseases (Hekimi 2006). The study of desirable phenotypes like longevity and healthy aging has been referred to as 'positive biology' (Farrelly 2012). Its premise is that understanding the basis for such desirable traits may allow us to design interventions to improve human health.

This review was intended to summarize our current understanding of genetic factors affecting the phenotypes of longevity and healthy aging in humans, including the definition and heritability of these traits, and linkage, association, and sequencing studies. The surprising and novel findings that centenarians do not appear to have a relative lack of common complex disease risk alleles, and that some genetic variants appear to 'buffer' or protect against specific risk alleles, are discussed in detail. Shorter summaries of the findings related to somatic mosaicism and the promising study of epigenetics of aging are included for completeness.

Aging, healthy aging, and longevity

The phenotypes used in studies of the genetics of human aging are usually lifespan (age at death), longevity (long life, usually defined as being a specific advanced age or older at the time of study), exceptional longevity (defined as attaining or exceeding a specific exceptional age), or healthy aging (a combination of old age and health, often defined as freedom from specific disorders or desirable performance levels on functional tests). Longevity studies focus on long-lived individuals (LLI), often centenarians aged 100 or more years. One advantage of such studies is the simplicity of phenotype definition. Healthy aging can be defined in various ways, usually with regard to reaching an at least moderately old age in the absence of certain diseases or disabilities, and/or in the presence of desirable traits such as intact cognition or mobility. Both types of studies should be differentiated from the study of the fundamental biological processes of aging (for example, cellular senescence).
A major difference between longevity and healthy aging studies is that the former focuses on lifespan, whereas the latter is focused on healthspan. Lifespan and healthspan are intimately related, however, and individuals who live exceptionally long also tend to be healthy for much of their lives. A landmark study of the health of supercentenarians (aged 110-119), semisupercentenarians (aged 105-109), centenarians (in this context aged 100-104), nonagenarians, and younger controls found that the older the age group, the greater the delay in onset of major disease (Andersen et al. 2012). Remarkably, for every category of increasing age, the hazard ratio for each of six disorders (cancer, cardiovascular disease (CVD), dementia, hypertension, osteoporosis, and stroke) was $<1.0$ relative to the next oldest group. This delay in disease development and postponement of cognitive and physical decline in the oldest group amounted to a compression of morbidity (Fries 1980). Based on these findings, Andersen et al. (2012) suggest that a realistic and practical limit of human lifespan is $110-115$ years, close to that of the oldest documented person in the world to date, who lived to 122 (Robine and Allard 1998).

Women have a lower mortality rate than men at every age, and women live longer than men in most human populations. Any given exceptional age, therefore, is more exceptional for men than for women. As noted by Sebastiani and Perls (2012) $1 \%$ of US women (but only $0.1 \%$ of men) born circa the turn of the last century lived to be 100 . Potential explanations for this difference include hormonal and immune differences, hemizygosity of the X-chromosome in men (which may allow manifestation of unfavorable sex-linked variants), and unrecognized confounders [reviewed in Newman and Murabito (2013)].

The heritability of lifespan and related traits

Age at death in adulthood has a heritability of approximately $25 \%$ (summarized in Murabito et al. 2012). A population-based study of 2,872 Danish twin pairs born between 1870 and 1900 found that the heritability of adult lifespan was 0.26 in men and 0.23 in women (Herskind et al. 1996). This cohort was not only population-based but nearly non-censored and, with follow-up for 94 years, encompassed essentially the entire human lifespan. Importantly, the heritability of longevity increases with greater age. The heritability of living to at least 100 has been estimated at 0.33 in women and 0.48 in men (Sebastiani and Perls 2012). Male and female siblings of US centenarians were 17-fold and eightfold more likely (compared with US Social Security data) to reach the age of 100, respectively (Perls et al. 2002). The increase in heritability of longevity at greater age is consistent between several studies. In over 20,000 Scandanavian twins, 
heritability of longevity was negligible from age 6-60, but increased with age thereafter (Hjelmborg et al. 2006). Long life was heritable in Icelanders aged over 70 years (Gudmundsson et al. 2000). The siblings of Okinawan centenarians show increased adult survival probability that starts at age 55 and increases with age (Willcox et al. 2006); the authors speculate based in part on absence of many age-related diseases from Okinawan (Bernstein et al. 2004) and other centenarians (Evert et al. 2003), that these individuals have genetic factors that confer resistance to such diseases and increase the likelihood of reaching exceptional old age. The estimation of heritability also depends on how it is studied; Murabito et al. (2012) note that the Framingham heart study cohorts give much greater estimates of heritability when longevity is studied as a dichotomous trait (36\% heritability for survival to 65 and $40 \%$ for survival to 85 ), compared with $16 \%$ heritability when age at death is treated as a continuous trait.

Clustering of longevity and healthy aging is observed in families. Parents of centenarians born in approximately 1870 were sevenfold more likely than their contemporaries to have lived to age 90-99; offspring of centenarian parents showed lower prevalence of age-related disease than agematched control groups (Atzmon et al. 2004). Exceptional familial clusters of extreme longevity have also been reported (Perls et al. 2000). Healthy aging is also heritable. Reed and Dick (2003) defined 'wellness' in male twins as achieving the age of 70 free of heart attack, coronary surgery, stroke, diabetes or prostate cancer, and showed that this trait had a heritability exceeding $50 \%$.

Environment and lifestyle likely constitute much of the remaining influence on human lifespan and healthspan. These factors have varied greatly over time and may not reflect the extrinsic factors that will affect the lifespan of babies born today. Many members of the elderly and centenarian cohorts under study today lived through times of caloric restriction (e.g., the Great Depression) and grew up before the use of antibiotics and vaccines became commonplace. The selective pressures that influenced their mortality are not identical to those experienced by later generations, and this is an important consideration for study design.

\section{The importance of study design}

Phenotype definition is particularly important in genetic studies; it affects the interpretation and meaning of results, and the ability to compare to the results of other studies. Studies of longevity can include extreme longevity (defined as living beyond a specific extreme age) or age at death. Studies of healthy aging may use age to disease onset, successful aging or wellness (which can also have a variety of definitions), or other phenotypes (Manolio 2007).
Linkage or family-based association study designs, longitudinal cohort studies, or case/control designs have been used. Family-based designs have the advantage of being robust to population stratification. Longitudinal cohorts have the advantage of limiting sampling bias, but take time and due to practical limits of size may not contain many individuals of extreme age. Sample size is a consideration for all these study designs. To date, the largest studies of LLI are in the low thousands of subjects; this is much smaller than the largest studies of common complex diseases (which now include over 100,000 subjects), despite the likely similar modest size of many of the genetic factors being sought.

Choice of a comparison group to contrast with exceptionally long-lived or exceptionally healthy elderly individuals is also critical. Health data for LLI can be compared with archived data for deceased individuals of the same birth cohort, but DNA samples from an ideal comparison group (such as their birth cohort) are not available. Case/control molecular genetic studies of longlived or healthy aged individuals often compare elderly cases to younger controls. Potential pitfalls of such studies include inadequate detection and control for population stratification, particularly for populations that have experienced immigration of different ethnicities over time (Nebel and Schreiber 2005). The use of principal components analysis (Price et al. 2006) or genomic controls (Devlin and Roeder 1999) can mitigate this problem, as can the conduct of studies within specific ethnic groups (Barzilai et al. 2001). In the case/control design, the control group is also expected to contain individuals who will go on to become equivalent to cases; their presence in the control group reduces power. Environmental factors must be acknowledged in such studies as potential confounders; inevitably, the cases and controls have lived in different times and experienced different lifestyles. A way to mitigate some of these problems; however, is to choose controls that are no older than 50 (Halaschek-Wiener et al. 2008) because in modern day developed countries, mortality before age 50 is minimal. Choosing a comparison group $<50$ years of age makes the control group essentially an 'unselected' group with regard to mortality from agerelated diseases. Choosing a control group in their 70 or 80 , however, would exacerbate this issue, as the control group would fail to include individuals who died in their 50's or 60's.

Several studies, such as the Longevity Gene Study (Barzilai et al. 2001), the Leiden Longevity Study (LLS) (Mooijaart et al. 2011), the New England Centenarian Study (NECS) (Terry et al. 2004), and the Long Life Family Study (LLFS) (Newman et al. 2011) include comparisons of the offspring of LLI (who are assumed to have inherited some longevity factors) to contemporary age- 
matched controls. They have observed that the offspring of LLI have more favorable blood lipid profiles (Barzilai et al. 2001; Newman et al. 2011) and lower prevalence of hypertension and metabolic and cardiovascular disease (Atzmon et al. 2004; Westendorp et al. 2009; Newman et al. 2011) and all-cause mortality (Terry et al. 2004) than age-matched controls. Comparison of the offspring of LLI with their contemporaries controls for cohort effects such as variation in BMI in human populations over time; it has the limitation, however, of under-estimating the difference in phenotypes and genotypes that would presumably be observed if the LLI could be compared with their largely long-deceased birth cohort.

\section{Linkage studies of longevity and healthy aging}

Linkage studies of long-lived sibships or extended pedigrees with exceptionally long-lived individuals have identified several putative and one replicated longevity linkage. In 2001, the NECS (Puca et al. 2001) reported a 10-cM sibpair based linkage scan of 308 individuals in 137 sibships with exceptional longevity (defined as having a proband of at least 98 and a 91-year-old male or 95-year-old female sib). They found significant evidence for linkage of longevity to a region around D4S1564. Suggestive support for this region was obtained through analysis of 95 concordant pairs of fraternal male twins with a wellness phenotype (age at least 70 with no overt CVD or prostate cancer) (Reed et al. 2004). Initial convergence of two linkage studies with very different phenotypes led to excitement about this region and its suspected role in longevity and health. Subsequent study of the region focused in part on a regional biological candidate gene, microsomal triglyceride transfer protein (MTP), identified through haplotype analysis (Geesaman et al. 2003).

In 2010 a larger and higher density linkage study (Boyden and Kunkel 2010) expanded on the initial NECS resource, with a genome-wide linkage study of 279 families with multiple long-lived sibs 90 years and older, including 129/137 of those previously described (Puca et al. 2001). A limitation of this study was the use of expected life span (estimated from age- and gender-specific life expectancies) for the $70 \%$ of subjects who were still living. This analysis of 9,751 SNPs found just-significant LOD scores at 3p22-24 and 9q31-34, as well as modest evidence for linkage at the original site, 4q22-25 and possibly at 12q. A larger study (Kerber et al. 2012) replicated the linkage of 3p22-24 to extreme longevity and identified possible additional loci. Working with 732 subjects from the Utah population database and database and population controls, including 433 Caucasian individuals aged 86-109 who showed a phenotype including both excess individual longevity (the difference between observed and expected lifespan) and excess familial longevity (a weighted average of excess longevity for all family members), they used a linkage screen with 1,100 microsatellite markers to identify a strongly suggestive peak at $3 \mathrm{p}$ at the same position as Boyden and Kunkel. Meta-analysis of linkage in the Utah and New England data sets supported linkage at the chromosome 3 locus. Other linkage peaks were observed in the Utah data at 18q23-24, $8 \mathrm{q} 23$, and $17 \mathrm{q} 21$; meta-analysis provided additional support but not outright replication for $8 \mathrm{q}, 9 \mathrm{q}$, and $17 \mathrm{q}$. The new data; however, did not support linkage to chromosome 4 or chromosome 12. Larger sample sets and denser and more informative linkage analyses were pointing away from the original chromosome 4 linkage observation, and converging instead most strongly at 3q24-22.

Two linkage studies of successful aging in Amish individuals over 80 years of age within a single 13-generation pedigree showed linkage to chromosomes 6,7 , and 14, different regions than those found in the longevity linkage studies. Successful aging was defined as cognitively intact and without depression, high functioning, and satisfied with life. These studies (Edwards et al. 2011; Edwards 2012) analyzed 263 cognitively intact Amish over 80 years old (74 successfully aged and 189 normally aged) within 12 sub-pedigrees using 630,309 autosomal SNPs. Linkage was found at $6 \mathrm{q} 25-27$, as well as association of a SNP, rs205990, in the interval linked to the 'successfully aged' phenotype. The chromosome 6 linkage identified in the Amish is different from those identified in the Utah and New England studies; this may reflect the different phenotype, or may be due to genetic factors specific to the Amish founder population.

The largest linkage study to date was done in the multisite European Genetics of Healthy Aging (GEHA) Study, which looked at 2118 European full sib-pairs over 90 years old (Beekman et al. 2013). GEHA found linkage at 4 regions: $14 q 11.2,17 q 12-q 22,19 p 13.3-p 13.11$, and 19q13.11-q13.32. The chromosome 14 linkage is at a different site from that observed in the Amish study; the large chromosome 17 region overlaps the 17q21 locus observed by Kerber et al. Fine mapping of these linkage regions using GWAS data in a subset of 1228 unrelated nonagenarians and 1907 controls identified a SNP near APOE at the $19 \mathrm{q}$ locus as significantly associated with longevity. Apolipoprotein $\mathrm{E}$ (apoE) isoforms are known risk factors for cardiovascular disease (CVD) and Alzheimer disease (AD), likely due to their involvement in inflammation, elevated lipid levels, and oxidative stress (Huebbe et al. 2011). ApoE has three main isoforms: apoE2, apoE3 and apoE4. Combined modeling in the GEHA study showed that APOE4 $(p=0.02)$ and APOE2 $\left(p=1.0 \times 10^{-5}\right)$ account for the linkage at $19 \mathrm{q}$. The $A P O E$ linkage was characterized by absence of APOE4, but enrichment for 
$A P O E 2$ among the nonagenarians. In this study the APOE2 allele is the stronger association, and the authors refer to $A P O E$ as a longevity gene.

The multiple linkage signals observed in these studies likely indicate genetic heterogeneity of longevity and healthy aging in human populations. Interestingly, the GEHA study observed heterogeneity among its multiple geographic regions; Northern European subjects contribute most to some of the linkage peaks they observe, including the $A P O E$ locus. Gender-specific effects were also observed, with a male-specific linkage peak at $8 \mathrm{p}$ and female-specific ones at $15 \mathrm{q}$ and the $19 \mathrm{q}$ APOE locus (Beekman et al. 2013). While the lack of association at the other linkage regions in the GEHA study may be due to power limitations, it could also imply that multiple rare or 'private' variants contribute to linkage but not association at these loci.

\section{Candidate gene association studies}

Candidate genes examined for association with longevity or healthy aging or related phenotypes fall into several categories. They include genes nominated based on observations of lifespan extension in model organisms; and genes involved in lipid metabolism, immune response and inflammation, stress response, and others. Candidate genes tested for association with longevity and related phenotypes have been the subject of several excellent reviews (Christensen et al. 2006; Wheeler and Kim 2011; Ferrario et al. 2012; Newman and Murabito 2013); an exhaustive listing is beyond the scope of this review.

Of the candidate genes assessed for association with longevity, variants in $A P O E$ and FOXO3A have been most consistently replicated, though some candidate genes have been associated with longevity phenotypes in more than one population but not in all populations tested; many more have been associated in a single study but failed to replicate in others (reviewed by (Christensen et al. 2006)). In a study of 1,344 healthy Italians aged 22-90, APOE4 was found at lower frequency and $A P O E 2$ at higher frequency in elderly and centenarians than in younger individuals (e.g., Seripa et al. 2006); APOE2 is a putative protective factor in this context and $A P O E 4$ can be considered a 'frailty' allele (Gerdes et al. 2000). FOXO3A is a homologue of the $C$. elegans Daf-16 gene that is important in control of lifespan in the worm (Hsin and Kenyon 1999); it is part of the insulin/IGF1 signaling pathway. FOXO3A variants have been associated with longevity in many populations (reviewed in Wheeler and Kim 2011).

Additional genes show promise of great relevance to healthy aging. A variant at CETP, for example, though inconsistently associated with longevity in different populations (reviewed by (Christensen et al. 2006)), in 213
Ashkenazi Jewish individuals of average age 98 is associated not only with longevity but also with additional aging-related phenotypes including a desirable lipid profile (Barzilai et al. 2003) and preservation of cognitive function (Barzilai et al. 2006). Other recent studies with extensive replication data are also encouraging. Association of a SNP in a heat shock factor gene, HSF2 with all-cause mortality was seen in the longitudinal Rotterdam Study (5,974 participants and 3,174 deaths), with replication in eight population-based cohorts (Broer 2012).

Other candidate genes have been associated with longevity or healthy aging phenotypes in some but not all studies. MTP, identified as a regional candidate at the $4 \mathrm{q} 25$ locus, failed to show replication of association with longevity in larger studies of approximately 1500 LLI each (Beekman et al. 2006; Bathum et al. 2005; Nebel et al. 2005). Progeria genes have shown association with longevity in some studies. A haplotype of SNPs at LMNA, the gene that is mutated in Hutchinson-Gilford progeria, was associated with long life (age $>95$ years) in 873 LLI and 443 controls, and remained significant upon meta-analysis of 3,619 subjects from four independent samples (Conneely et al. 2012). Polymorphisms at WRN have shown inconsistent associations with age (Castro et al. 2000; Kuningas et al. 2006). Sirtuins mediate the effects of caloric restriction, a non-genetic factor known to increase life span in many organisms. The effect of polymorphisms in sirtuin genes (SIRT1-7) on longevity and age-related diseases was reviewed by Polito et al. (2010). There is evidence that variants in SIRT3 (Rose et al. 2003) are associated with longevity. A functional promoter variant at DNA repair gene EXO1 was associated with longevity in female centenarians (Nebel et al. 2009), but tagSNPs in the gene showed no association with longevity in men (Morris 2013).

Given the multifactorial nature and likely genetic heterogeneity of healthy aging and longevity, as well as environmental influences on these complex traits, it may not be reasonable to expect that replication of candidate gene studies would be uniform between populations. Reasons for lack of replication include limitations of sample size, rarity (low minor allele frequency) of actual variants, and small true effect sizes. Poorly designed or underpowered studies will result in false positives that legitimately fail to replicate. For studies of longevity and healthy aging, in particular, differences in phenotype or type of study will also result in findings that are non-uniform between studies. While larger case/control studies are frequently suggested as a solution to the limitations of present-day association studies, combining data from populations with different lifestyles and genetic backgrounds, even if well-matched for ethnicity, may obscure true association signals. 
Genome-wide association studies

To date, SNPs in or near APOE are the only ones to achieve genome-wide significance (GWS, generally $p \leq 5 \times 10^{-8}$ ) in genome-wide association studies (GWAS) of lifespan-related traits. In three GWAS of longlived individuals vs. younger controls, $A P O E$ was significantly associated with longevity at the genome-wide level. The first of these included 763 long lived (94-110 years) and 1,085 control (45-77 years) from German biobanks and replication in an independent set of German samples (754 cases aged 95-108, 860 controls aged 60-75) (Nebel et al. 2011). Only rs4420638 near APOC1 and in linkage disequilibrium (LD) with $A P O E$ achieved GWS. GWAS of 403 unrelated nonagenarians (average age 94) from longevity families in the LLS vs. 1,670 controls (average age 58) showed similar results (Deelen et al. 2011a). Only one of 62 SNPs carried forward to meta-analysis with 4,149 nonagenarian cases and 7,582 younger controls from the Rotterdam study, the Leiden $85+$ study and the Danish 1905 Cohort reached GWS, rs2075650 at TOMM40 near APOE. Meta-analysis of the APOE2 and APOE4 SNPs showed significant associations of both SNPs with longevity, with E2 being protective of long life (OR 1.31, CI 1.17-1.46, $p=1.35 \times 10^{-6}$ ), and E4 being deleterious (OR 0.62, CI $0.56-0.68, p=1.33 \times 10^{-23}$ ). A third longevity GWAS (Sebastiani et al. 2012) included three phases: a discovery phase with 801 New England centenarians (aged 95-119, many with a family history of extreme longevity) vs. 914 controls genetically matched by means of principal components analysis; a first replication in 253 centenarians (89-114) vs. 341 genetically matched controls; and a second replication with 60 additional centenarians (100-114) and unmatched controls. Of 243,980 SNPs analyzed only one, TOMM40 SNP rs2075650 near $A P O E$, reached GWS. Inverse association of APOE4 with longevity $\left(p=5.3 \times 10^{-3}\right)$ was also detectable in the Southern Italian centenarians study (SICS) of 440 LLIs aged 90-109 and 553 young controls aged 18-45 (Malovini et al. 2011), despite the known lower frequency of the E4 allele in Southern, as compared with Northern, Europe (Haddy 2002).

Other GWAS of lifespan-related phenotypes revealed no associations that were significant at the genome-wide level. A GWAS of the Framingham health study (Lunetta et al. 2007) (258 Original Cohort and 1,087 Offspring individuals, members of the 330 largest families in the study) revealed no GWS SNPs for any of five aging-related phenotypes. Newman et al. (Newman et al. 2010) meta-analyzed four cohort studies in the cohorts for heart and aging research in genomic epidemiology (CHARGE) Consortium for survival to at least 90 years of age. Cases were 1,836 people who achieved survival to at least 90; controls were 1,955 participants who died aged 55-80. SNPs were genotyped and imputed in subjects of European ancestry, with systematic elimination of outliers and correction for population stratification. Replication was carried out in the LLS (950 long-lived probands and 744 partners of their offspring and 680 blood bank donors) and the Danish 1905 Cohort Survey (2,262 long-lived participants and 2007 Danish twin study controls aged 46-68). No SNPs reached genomewide significance.

Walter et al. (2011) conducted a meta-analysis of GWAS of nine longitudinal cohort studies in the CHARGE Consortium, including 25,000 unselected people of European ancestry. They analyzed two continuous traits, allcause mortality, and event-free survival (where 'event' was defined as myocardial infarction, heart failure, stroke, dementia, hip fracture, or cancer). No SNPs reached GWS for either phenotype. SNPs near APOE reached only nominal significance in the CHARGE study (Walter et al. 2011), in contrast to the results of GWAS of centenarians, in which $A P O E$ has been a significant and replicable finding. The CHARGE meta-analysis contained few extremely old individuals, and so in comparison with centenarian studies or those targeting long-lived healthy individuals, has examined earlier mortality and events, a different phenotype. The Framingham Study GWAS (Lunetta et al. 2007), which also showed no GWS SNPs also represents a much younger group, on average, than studies of oldest old or centenarians. This may mean that different genes and variants may come into play in different phases of aging, with $A P O E$ being most relevant at older ages. Earlier mortality is often related to lifestyle as well, and the heritability of aging is lower at younger ages, as described above.

A genome-wide association study of copy number variants (CNVs) in the Rotterdam study RS1 cohort, with replication in the RS2 cohort and the FHS, found that large common deletions are associated with mortality (vs. survival) at old age (Kuningas et al. 2011a). They tested 312 common $\mathrm{CNV}$ regions and measures of $\mathrm{CNV}$ burden for association with mortality during follow-up. A higher burden of CNVs of $500 \mathrm{~kb}$ or more in size was associated with mortality. Two specific regions were also associated with mortality, $11 \mathrm{p} 15.5$ and $14 \mathrm{q} 21.3$. The $11 \mathrm{p} 15.5$ association, which would survive Bonferroni correction for 312 tests, includes insertions and deletions which were analyzed together relative to non-carriers; it contains 41 genes including some related to longevity or complex diseases. The $14 \mathrm{q} 21.3$ region contains no genes and is characterized only by deletions. Runs of homozygosity, which can indicate presence of recessive loci, were not associated with survival to old age in this cohort (Kuningas et al. 2011b). 
Analyses of phenotypes that may influence long-term good health have also been undertaken. Personality traits are associated with healthy aging and longevity (Terracciano et al. 2008). In the LLFS, a GWAS of five personality factors in 583 families with 4,595 individuals and replication in 1,279 other subjects identified a locus associated with agreeableness, and identified several significant age $\times$ SNP interactions that may affect longevity through effects on personality (Bae et al. 2013).

In contrast to the results of longevity GWAS, GWAS of common complex diseases have revealed hundreds of SNPs associated with cancers, CVD, diabetes and other age-related diseases, albeit with increasing numbers of associations found with increasing GWAS size. One explanation for this may be that the phenotypes of healthy aging and longevity may be much more complex than those of these complex diseases, in part because they often (depending on phenotype definition) involve absence of specific complex diseases. If GWAS studies of survival to elderly ages are even more confounded by environmental (E) factors than GWAS of diseases, combining studies from different populations in pooled or meta-analyses may complicate the $\mathrm{E}$ effects even more. In studies of older individuals, it is particularly hard to control for $\mathrm{E}$ factors experienced over many decades of life.

Effects of variants that do not achieve $p \leq 5 \times 10^{-8}$

SNPs at only one locus, APOE, have achieved Bonferronicorrected levels of GWS in GWAS of longevity. By current standards these GWAS, which involved fewer than 1,000 centenarians, or a few 1,000 nonagenarians, are modest in size. Larger GWAS may in theory allow additional SNPs to achieve this threshold. There are other indications, however, that support the idea that SNPs that do not reach this threshold of GWS may be biologically important, either individually or through their joint effects. Several studies used a variety of techniques to analyze collections of nominally longevity-associated SNPs to determine if they act in concert to affect lifespan.

In the Framingham study GWAS of 5 aging-related phenotypes (Lunetta et al. 2007) observed that SNPs in some candidate genes, including SNPs near the Werner syndrome gene $W R N$ and FOXOIA, as well as GAPDH, $K L$, LEPR, PON1, PSEN1, and SOD2 were associated with age at death. Kulminski and Culminskaya (2011) used Framingham Affymetrix $50 \mathrm{~K}$ SNP data to perform GWAS of four endophenotypes (CVD, cancer, systolic blood pressure, and total cholesterol) to identify 63 SNPs that were associated at $p<10^{-6}$ with at least one endophenotype. 76 genes at or near these SNPs were enriched in terms of Gene Ontology annotations related to aging-relevant processes. Yashin et al. (2010) hypothesized that lifespan depends on the number of small-effect longevity alleles present in individual genomes. They re-analyzed Framingham $550 \mathrm{~K}$ SNP data and identified 169 SNPs associated at $p<10^{-6}$. The number of these SNPs carried by an individual correlated with lifespan and explained $21 \%$ of its variance; in contrast, randomly chosen SNPs did not correlate with lifespan.

Gene set analysis of GWAS data from the LLS and Rotterdam studies was used to show that genes in the insulin/IGF-1 signaling (IIS) and telomere maintenance TM pathways are associated with longevity (Deelen 2011b). 1021 and 88 GWAS SNPs were identified within $10 \mathrm{~kb}$ of 68 IIS and 13 TM genes, respectively. Both pathways were associated with longevity. Nine IIS genes (AKT1, AKT3, FOXO4, IGF2, INS, PIK3CA, SGK, SGK2, and $Y W H A G)$ and one TM gene (POT1) were the main determinants of the association.

Sebastiani et al. (2012) constructed a model in which 281 SNPs showed $89 \%$ sensitivity and $89 \%$ specificity to predict longevity in their GWAS Discovery set, and 58-61\% specificity and 58-85\% sensitivity in independent sets. They call this a 'genetic signature of exceptional longevity'. These SNPs explain nearly $20 \%$ of the heritability of extreme longevity. They find that the TOMM4O SNP near APOE alone has poor predictive value; removing it from the model reduces specificity and sensitivity by only $1 \%$. The 281 SNPs include 137 in 130 genes, including LMNA, WRN, SOD2, CDKN2A, SORCS1 and SORCS2, and GIP. This set of 130 genes is highly and significantly enriched for those related to Alzheimer disease (38 genes), 42 related to dementia, 38 to tauopathies, 24 to CAD, and several to neoplasms.

GWAS of the SICS Study of 410 LLI and 553 younger controls identified 67 SNPs that reached a permutationdefined level of genome-wide significance of $p<10^{-4}$ (Malovini et al. 2011). Among them was rs10491334 at the calcium/calmodulin-dependent protein kinase IV (CAMKIV) that replicated in 116 additional LLI and 160 controls. Malovini et al. demonstrate that CAMK4 phosphorylates and activates survival proteins FOXO3A, AKT, and SIRT1. Homozygous carriers of the minor allele had lower CAMKIV protein expression and were underrepresented among LLI's, consistent with a deleterious effect of this allele on longevity.

The biological relevance of other SNPs besides those at $A P O E$ is also strongly supported by similarities between the results of human GWAS and mouse lifespan studies. Eight of the ten top CHARGE SNPs detected by GWAS, but which did not achieve GWS, correspond to mouse lifespan quantitative trait loci (QTL) (Murabito et al. 2012). These studies connect GWAS findings that do not reach GWS with many genes that are relevant to aging or age-related diseases. In several cases, this convergence 
with genes of biological interest is statistically unlikely to be due to chance and is likely to reflect the presence of true association signals that are not consistent enough to be replicated predictably as candidate genes or achieve GWS, or have effects that are too subtle to be detected individually. Such potential true signals may be more affected by ' $E$ ' factors than those that have been replicated, i.e., $A P O E$ and $F O X O 3 A$. As pointed out by Yashin et al., the same sets of variants would not be expected to work in all populations because of differences in environment (Yashin et al. 2010).

The extremely long-lived do not lack risk alleles for common complex diseases

Several recent studies have shown that centenarians do not carry smaller numbers of risk alleles for common complex diseases than average people. In an important paper in 2010, Beekman et al. (2010) studied two case/control collections: (1) 723 nonagenarian siblings (mean age 94) from the LLS vs. 721 unrelated younger controls (mean age 52), and (2) 979 long-lived individuals over 85 (mean age 87) from the pop-based Leiden $85+$ study vs. 1,167 younger controls (mean age 41) from the Netherlands Twin Register. They looked at 30 SNPs known to be associated with CVD, cancer or type 2 diabetes (T2D). The cases and controls each carried an average of 27 disease risk alleles. The distribution of risk alleles was the same in elderly and young subjects. Beekman et al. note that "GWAS-identified disease risk alleles do not compromise human longevity" and suggest that a lack of rare disease factors, or the presence of protective factors, is at work in the longlived individuals. It is important to note, however, that CVD, cancer, and T2D are diseases that have very clear lifestyle components and that part of the effect could be due to lifestyle differences.

Mooijaart et al. (2011) extended this observation the following year, showing that "SNPs associated with T2D and identified by GWAS are not major determinants of the beneficial glucose tolerance that characterizes familial longevity." They compared the offspring of the LLS longlived individuals with the offspring's spouses and other controls. The LLS offspring had a better metabolic profile and better glucose tolerance than same-age controls, although the frequency of 15 known T2D SNPs did not differ between the two groups. When individuals were compared within each group, however, glucose levels did correlate with the number of T2D SNPs. They speculate that the LLS offspring may have protective factors that improve their metabolic profile and glucose tolerance in spite of the presence of T2D GWAS SNPs. This comparison, using same-age groups of individuals, clearly points to protective genetic factors contributing to preservation of a healthy phenotype, rather than lifestyle and environmental factors that should be very similar (at least in adulthood) between the offspring and their spouses.

Sebastiani et al. (2012) also noted that there was not a substantial difference in the numbers of 1,214 known disease-associated SNPs in centenarians and controls. A similar observation was made in their whole genome sequence data from one male and one female supercentenarian (Sebastiani et al. 2011).

These important and perhaps surprising results show that extreme longevity, and the long-term good health that often accompanies it, is not incompatible with the presence of many disease risk alleles. At least for the common SNPs associated with common complex diseases, it is not the absence of 'bad' alleles, but more likely the presence of 'good' alleles that influences longevity, though effects of 'good' environmental factors may also contribute. Protective factors of some kind may allow these risk variants to not be manifest. These results also have implications beyond the study of longevity - in an age when substantial effort is being invested in personalized disease risk prediction, the presence of many disease alleles that are nonpenetrant in some individuals potentially complicates predictions of disease.

Do 'good' variants protect against 'bad' ones?

One mechanism for a lack of effect by an undesirable allele is the 'buffering' mechanism explored by Barzilai et al. They propose that some individuals who show exceptional longevity may do so despite the presence of unfavorable alleles because those alleles are buffered by favorable alleles in other genes (Bergman et al. 2007). They suggest that buffering gene variants (longevity variants) will show a monotonic increase in frequency from early old age (65) to later ages; examples of buffering genotypes are CETP $\mathrm{VV}, A P O C 3 \mathrm{CC}$, and a +2019 deletion in $A D I P O Q$. Buffered alleles, in contrast, should show a U-shaped frequency curve, higher at younger ages, dipping low in early old age, and then increasing in the exceptionally old (who have the 'buffering' protective genotype that allows disease-related variants to accumulate); examples of buffered genotypes are heterozygotes for deleterious alleles of KLOTHO and LPA. Importantly, Bergman et al. use a cross-sectional study design, with 1,200 subjects in their 6-11th decades of life to show experimental support for the buffering hypothesis; their data support the idea that CETP VV genotype buffers the deleterious effects of an LPA genotype. They show a genetic interaction between CETP genotype and LPA; LPA heterozygotes with the CETP IV/ II genotypes monotonically decrease in frequency with age, but those in CETP VV individuals increase from age 70 onward. They argue that case/control analyses are 
insufficient to reveal this effect because it does not reveal the shape of the allele frequency $\times$ age curve.

Earlier observations are also explained by a buffering mechanism. De Benedictis et al. (1998) described an agerelated convex trajectory of a $3^{\prime} A P O B$-VNTR genotype that they interpret as consistent with crossing mortality curves relevant to subgroups of individuals with different genotypes. A X-sectional study of 800 healthy aging subjects from 18 to 109 years free of clinically apparent disease genotyped variants in APOA1, APOC 3 , and APOA4 (Garasto et al. 2003). They noted that an allele of APOAI that correlated with higher serum LDL-C was paradoxically increased in frequency in the oldest old. The authors called it "another genetic paradox of centenarians." While this observation could reflect population stratification in the different age groups, it may also be due to the U-shaped curve of a buffered gene.

The buffering mechanism may also explain some of the inconsistency in the findings for MTP. Huffman et al. (2012) find that MTP CC is a deleterious genotype that is buffered by any of three longevity genotypes of CETP, $A P O C 3$, or $A D I P O Q$. MTP CC shows a U-shaped curve, declining ages $55-85$, and then dramatically increasing in those who live 90 or more years. If this MTP genotype is observed at high frequency in centenarians, but only in the presence of specific protective variants, this may in part explain why the linkage at chromosome 4 was not observed consistently between studies.

Buffering has been described in model organisms. The heat-shock protein Hsp90 is known to buffer genetic variation in Drosophila, allowing it to accumulate under neutral conditions (Rutherford and Lindquist 1998). Such a gene is known as a phenotypic capacitor, and it masks the presence of phenotypic variation. It is interesting to speculate that protective genetic variants carried by centenarians may be capacitors for the disease risk variants we now know they carry at, on average, the same frequency as other people. Identification of buffering/capacitor genes and study of their function will be necessary to understand the longevity phenotype. It will also be important to determine if such capacitors operate in healthy aging as well as extreme longevity. Because such variants are likely rare, intensive study of rare individuals at the upper ends of the human lifespan and healthspan, perhaps by whole genome sequencing and examination of unusual variants they carry, is paramount.

The interaction between buffering and buffered genes and genotypes also has implications for study design. The exquisite studies carried out by Barzilai's group are done in a single well-defined ethnicity, Ashkenazi Jewish individuals. Since a buffered gene will only show a distinctive U-shaped curve in the presence of its buffer, and a buffer may only be advantageous in the presence of a deleterious gene that it buffers, this underscores the importance of avoiding population stratification in such studies. If some of the associations detected to date in case/control studies of healthy aging and longevity are actually underlain by genotypes with U-shaped curves, the choice of ages for the cases and controls will greatly affect whether an association is detected, and may explain some failures of associations to replicate. Finally, the concept of buffering genes has implications for the use of centenarians, or exceptionally healthy elderly individuals as super-controls for disease studies; if the exceptional elderly are healthy because of a protective factor rather than lack of a disease allele, their use as an extreme comparison group may not necessarily be helpful.

Do differences in lifestyle affect these studies?

Given that lifestyle is expected to have a greater impact than genetics on healthy aging, it seems unlikely that differences in lifestyle are not confounding association studies of longevity and healthy aging. It is challenging to quantify lifestyle in an optimal comparison group for, for example, centenarians. Younger control groups inevitably have different lifestyles than the elderly had at their age. For example, the CHARGE consortium (Newman et al. 2010), which compared individuals who survived to at least 90 to those who died aged 55-80, found that the younger controls had higher rates of smoking.

The Longevity Gene Study overcame the birth cohort limitation using pre-existing lifestyle data from 3,164 NHANES controls of the same birth cohort as 477 Ashkenazi Jewish individuals aged 96-109 (Rajpathak et al. 2011). They found no obvious differences in lifestyle and suggested that the long-lived individuals may interact with lifestyle factors differently than others. This study, however, did note subtle differences between the long-lived and comparison groups. They saw significantly fewer obese men, more overweight women, and fewer obese women in the long-lived group; in addition, more control men smoked. These differences, combined with recall limitations of the long-lived group, imply that this analysis may have missed many small lifestyle differences that could add up to substantial health differences. It will likely be difficult to take into account all but the largest lifestyle factors when planning GxE studies of longevity and healthy aging. Biomarkers of exposures may vary not only with exposure but also over time, complicating the use of such methods for these phenotypes.

Association studies of mitochondrial variants

Mitochondria are thought to be important to aging due to their key roles in oxidative phosphorylation, cell 
metabolism, and apoptosis. A relationship of variation in the mitochondrial genome with health and/or longevity is implied by the observation that age at death correlates more closely with the age at death of a person's mother more so than that of the father (Brand et al. 1992). Associations of mitochondrial genome sequence variants or haplogroups (combinations of specific variants that correlate with specific populations) with healthy aging or longevity have been noted in many populations including, for example, Italian (De Benedictis et al. 1999), Japanese (Tanaka et al. 1998), Amish (Courtenay et al. 2012), Chinese Uygur (Ren et al. 2008), Costa Rican (Castri et al. 2009), Ashkenazi Jewish (Iwata et al. 2007), Irish (Ross et al. 2001), and Finnish individuals (Niemi et al. 2003). The associations observed are inconsistent between populations and do not involve the same variant or haplogroup. This lack of consistency may be due in part to the relatively small size of many of these studies. Three common problems have been noted about such studies: inadequate matching of cases and controls, inadequate correction for multiple tests, and undetected population stratification (Shlush et al. 2008).

Interestingly, when the frequencies of different mitochondrial haplogroups are plotted for Italian individuals aged 20 to over 100 , the curve shapes observed include monotonic increase for haplogroup J, and a U-shaped curve for haplotype $\mathrm{H}$ (de Benedictis et al. 2000), reminiscent of the 'longevity' and 'buffered' variants described earlier. A variant at the origin of replication of the mitochondrial heavy strand, C150T, has been observed at higher frequencies in centenarians, both through inheritance and through somatic increase in frequency, with some individuals achieving homoplasmy for this variant in their lymphocytes and monocytes, but not in granulocytes; a selective advantage of achieving high frequency of this variant in at least some cell types has been suggested (Zhang et al. 2003). Interactions between nuclear genome variants and both inherited and somatic mitochondrial variants have also been suggested to play a role in aging and longevity (Santoro et al. 2006; Tranah 2011).

\section{Genome sequencing}

Sebastiani et al. (2011) recently reported the whole genome sequencing of one male and one female supercentenarian of European ancestry from the NECS. The genomes of these exceptionally long-lived individuals were similar, in terms of the rate of nonsynonymous SNPs and number of indels, to other genomes sequenced to date. They have a similar number of known disease-associated variants to other genomes showing that their exceptional lifespan does not seem to be due to lack of known disease-associated variants. It is possible, though, that they failed to inherit a combination of variants that would have acted together to cause disease. Both supercentenarians lacked APOE4 alleles. They do not carry most of the longevity variants reported previously in the literature, implying that these known variants are not necessary for longevity. It is possible that they carry as yet undiscovered protective variants. One per cent of the variants observed were novel. Interestingly, an excess of coding region variants was seen in genes closest to GWAS-identified longevity variants, an observation that supports the idea that rare variants of these genes may contribute to the longevity phenotype.

Telomeres in healthy aging and longevity

Telomeres are indisputably important to aging. Telomeres shorten with age and are considered to be a biomarker of age. The role of telomere biology in healthy aging and disease was recently reviewed (Zhu et al. 2011). Leukocyte telomere length (LTL) has been correlated with measures of health and ability in elderly individuals. In a community-based cohort of 70- to 79-year-olds, LTL was associated with more years of healthy life; LTL was suggested to be a biomarker of healthy aging (Njajou et al. 2009). Louisiana Healthy Aging Study results concurred with this observation; LTL was correlated with measures of healthy aging in an age-dependent way (Kim et al. 2012). LTL was also found to correlate positively with physical ability (but not cognitive function) in Danish twins aged at least 77 years (Bendix et al. 2011) and inversely with disability in American seniors (Risques et al. 2010). Ashkenazi centenarians and their offspring also showed longer telomeres, for their age, than controls; longer telomeres correlated with less disease (Atzmon et al. 2010). In contrast, in a study of Canadian 'Super-Seniors' (individuals aged at least 85 and never diagnosed with cancer, cardiovascular disease, Alzheimer disease, major pulmonary disease or diabetes) the healthy oldest-old did not have exceptional telomere length for their age, but showed less variability in telomere length than mid-life controls, implying that they may be selected for optimal rather than extreme telomere length (Halaschek-Wiener et al. 2008).

Variation in genes involved in telomere maintenance has also been associated with longevity. One SNP at SIRTI (Kim et al. 2012) and one in TERC (Soerensen et al. 2012) are associated with both LTL and longevity. Detailed analysis of TERT and TERC in Ashkenazi centenarians showed an excess of genetic variation in both genes in the centenarians and identified a TERT haplotype associated with extreme longevity (Atzmon et al. 2010). Gene set analysis of GWAS data also supported the relevance of telomere maintenance (Deelen et al. 2013). Overall, the relationship between telomeres, aging, healthy aging, and longevity is multi-layered. Telomere maintenance is an 
important process in aging, and also a biomarker of it. LTL is a biomarker of aging and of healthy aging. Variation in telomere maintenance genes appears to affect both telomere length, and life span and health span in humans.

\section{Somatic genetics of aging}

Two recent large-scale analyses of data from GWAS studies have established that mosaicism for large genomic alterations increases with age (Laurie et al. 2012; Jacobs et al. 2012). In one study, data for 50,222 subjects found that $<0.5 \%$ of people aged $<50$, and $2-3 \%$ of elderly ( $2.7 \%$ in subjects $>80$ years), have detectable mosaicism in peripheral blood. Age was a significant predictor of mosaic status, but sex, ancestry, and smoking status were not. The second study used data from 31,717 cancer cases and 26,136 controls from 13 GWAS studies and found detectable clonal mosaicism in $0.87 \%$ of individuals. In the cancer-free controls, they found mosaicism in $0.23 \%$ of those $<50$ years old and in $1.91 \%$ of those aged $75-79$, a significant difference $\left(p=4.8 \times 10^{-8}\right)$. Somatic mosaicism (heteroplasmy) of the mitochondrial genome also increases over the lifespan (Sondheimer et al. 2011). Of course, telomere shortening is another somatic genomic change that occurs over the human lifespan. Such somatic changes are both a genetic aspect of aging and an agingrelated phenotype.

\section{Epigenetics and longevity/aging}

Epigenetics, at the interface between the genome and the environment, is emerging as an important factor in longevity, and has been the subject of recent excellent reviews (Gravina and Vijg 2010; Ben-Avraham et al. 2012). Methylation patterns change with age, and discordance in methylation between MZ twins also increases with age (Talens et al. 2012), an observation consistent with the effect of environment and lifestyle on the epigenome. Studies of DNA methylation support the idea that aging is associated with a relaxation of epigenetic control and that this epigenetic drift may affect the development of agingrelated diseases (Gravina and Vijg 2010). An epigenomewide association scan (EWAS) identified age-related differentially methylated regions as well as differentially methylated regions associated with age-related phenotypes (Bell et al. 2012). Whole genome bisulfite sequencing of DNA from $\mathrm{CD}^{+}{ }^{+} \mathrm{T}$ cells of a centenarian and a newborn identified differentially methylated regions that were usually hypomethylated and less correlated with methylation of adjacent $\mathrm{CpG}$ dinucleotides in the centenarian (Heyn et al. 2012). These results support the idea that small cumulative DNA methylation changes accumulate over a lifetime. Age-related temporal changes in DNA methylation also show significant familial clustering, indicating that methylation maintenance is a familial trait (Bjornsson et al. 2008). A study of DNA methylation in centenarians and their offspring compared with the offspring of non-long-lived individuals and young individuals showed that the offspring of the centenarians delay agerelated methylation changes (Gentilini 2012). A landmark paper by Hannum et al. (2013) offers an explanation for this familiality. They used methylome analysis to compare human aging rates in individuals of age 19-101 and identify methylation QTLs (meQTLs) (including one at methylCpG binding domain protein 4) that affect it. Indeed, transgenerational epigenetic inheritance of extended lifespan has been demonstrated in C. elegans (Greer et al. 2011).

It is likely that the effects of epigenetic changes manifest in part by effects on gene expression. Longevityselected lines of Drosophila show gene expression profiles that are similar to younger control flies (Sarup et al. 2011). This type of observation is more difficult to make in humans, however. Several human studies have compared gene expression between LLI and younger individuals. Blood miRNA expression differences between LLI and younger controls identified genes known to be differentially expressed in age-related diseases (ElSharawy et al. 2012). This study design, however, does not allow discrimination between genes that are differentially expressed because they are involved in longevity, related to chronological age, or affected by environmental differences between the old and young groups. A cross-sectional analysis of individuals aged 50-90, and centenarians, was used to identify a miRNA, miR-363*, whose expression declined with age but was preserved at youthful levels in the centenarians (Gombar et al. 2012). The Leiden Longevity Study, however, used LLI and their offspring to show that RPTOR in the mTOR pathway is differentially expressed between the offspring of the LLI and their spouses (Passtoors et al. 2013). The study design issues that are important to avoid confounding by lifestyle factors in studies of inherited factors will be even more important in gene expression studies. It seems likely that as yet unidentified genetic factors and lifestyle practices that help us maintain a favorable epigenetic profile and optimal gene expression will be important in longevity and healthy aging.

\section{Conclusions}

To date, studies of longevity and healthy aging have shown few consistent and many inconsistent results. This is probably due in part to the nature of the variants we seek to find, which may be rare or even private, may act in concert or as a 'signature', and which may buffer against the 
presence of other variants. It is also due to inter-ethnic differences, population stratification, differences in phenotype definition and study design, effects of and confounding by known and unrecognized non-genetic factors in part due to cohort effects, and exacerbation by insufficient sample size. Nevertheless, the results of longevity studies to date establish their importance for our understanding of health and disease.

Only one gene has emerged as consistently found in studies of LLI, APOE, though another, FOXO3A, was replicated in multiple candidate gene studies. Additional candidate genes are associated in more than one but not all studies. Many of these correspond to signals that hover below GWS in GWAS studies, and when analyzed together for commonalities of pathways or other processes by means such as gene set analysis, as a group are significantly associated with these phenotypes. Epigenetics is quickly emerging as a critical aspect of aging and longevity. Centenarians delay age-related methylation changes, and they can pass this methylation preservation ability on to their offspring, probably via genetic variants that affect methylation QTLs.

Importantly and perhaps surprisingly, centenarians appear to have the same numbers of GWAS-identified common disease variants as ordinary people, and yet they have lived long and, to a great extent, free of disease. Specific examples support the idea that centenarians may have advantageous alleles of 'buffering' genes that allow them to remain healthy despite the presence of 'buffered' deleterious alleles in other genes. It will be important to determine how generalizeable this is-does it apply only to a few genes, or is it a general mechanism for suppression of disadvantageous alleles of many genes? As others have pointed out (Bergman et al. 2007), a longevity gene that buffered frailty alleles in several other genes would be a desirable drug development tool. Understanding this will affect not only personalized medicine but also our overall interpretation of genomes, and could even give us the information needed for rational design of agents to recreate this desirable scenario in those not lucky enough to inherit it.

Open Access This article is distributed under the terms of the Creative Commons Attribution License which permits any use, distribution, and reproduction in any medium, provided the original author(s) and the source are credited.

\section{References}

Andersen SL, Sebastiani P, Dworkis DA, Feldman L, Perls TT (2012) Health span approximates life span among many supercentenarians: compression of morbidity at the approximate limit of life span. J Gerontol A Biol Sci Med Sci 67:395-405
Atzmon G, Schechter C, Greiner W, Davidson D, Rennert G, Barzilai N (2004) Clinical phenotype of families with longevity. J Am Geriatr Soc 52:274-277

Atzmon G, Cho M, Cawthon RM, Budagov T, Katz M, Yang X, Siegel G, Bergman A, Huffman DM, Schechter CB, Wright WE, Shay JW, Barzilai N, Govindaraju DR, Suh Y (2010) Evolution in health and medicine Sackler colloquium: genetic variation in human telomerase is associated with telomere length in Ashkenazi centenarians. Proc Natl Acad Sci USA 107(Suppl 1):1710-1717

Ayyadevara S, Alla R, Thaden JJ, Shmookler Reis RJ (2008) Remarkable longevity and stress resistance of nematode PI3 Knull mutants. Aging Cell 7:13-22

Bae HT, Sebastiani P, Sun JX, Andersen SL, Daw EW, Terracciano A, Ferrucci L, Perls TT (2013) Genome-wide association study of personality traits in the long life family study. Front Genet 4:65

Barzilai N, Gabriely I, Gabriely M, Iankowitz N, Sorkin JD (2001) Offspring of centenarians have a favorable lipid profile. J Am Geriatr Soc 49:76-79

Barzilai N, Atzmon G, Schechter C, Schaefer EJ, Cupples AL, Lipton R, Cheng S, Shuldiner AR (2003) Unique lipoprotein phenotype and genotype associated with exceptional longevity. JAMA 290:2030-2040

Barzilai N, Atzmon G, Derby CA, Bauman JM, Lipton RB (2006) A genotype of exceptional longevity is associated with preservation of cognitive function. Neurology 67:2170-2175

Bathum L, Christiansen L, Tan Q, Vaupel J, Jeune B, Christensen K (2005) No evidence for an association between extreme longevity and microsomal transfer protein polymorphisms in a longitudinal study of 1651 nonagenarians. Eur J Hum Genet 13: $1154-1158$

Beekman M, Blauw GJ, Houwing-Duistermaat JJ, Brandt BW, Westendorp RG, Slagboom PE (2006) Chromosome 4q25, microsomal transfer protein gene, and human longevity: novel data and a meta-analysis of association studies. J Gerontol A Biol Sci Med Sci 61:355-362

Beekman M, Nederstigt C, Suchiman HE, Kremer D, van der Breggen R, Lakenberg N, Alemayehu WG, de Craen AJ, Westendorp RG, Boomsma DI, de Geus EJ, Houwing-Duistermaat JJ, Heijmans BT, Slagboom PE (2010) Genome-wide association study (GWAS)-identified disease risk alleles do not compromise human longevity. Proc Natl Acad Sci USA 107:18046-18049

Beekman M, Blanche H, Perola M, Hervonen A, Bezrukov V, Sikora E, Flachsbart F, Christiansen L, De Craen AJ, Kirkwood TB, Rea IM, Poulain M, Robine JM, Valensin S, Stazi MA, Passarino G, Deiana L, Gonos ES, Paternoster L, Sorensen TI, Tan Q, Helmer Q, van den Akker EB, Deelen J, Martella F, Cordell HJ, Ayers KL, Vaupel JW, Tornwall O, Johnson TE, Schreiber S, Lathrop M, Skytthe A, Westendorp RG, Christensen K, Gampe J, Nebel A, Houwing-Duistermaat JJ, Slagboom PE, Franceschi C (2013) Genome-wide linkage analysis for human longevity: genetics of healthy aging study. Aging Cell 12:184-193

Bell JT, Tsai PC, Yang TP, Pidsley R, Nisbet J, Glass D, Mangino M, Zhai G, Zhang F, Valdes A, Shin SY, Dempster EL, Murray RM, Grundberg E, Hedman AK, Nica A, Small KS, Dermitzakis ET, McCarthy MI, Mill J, Spector TD, Deloukas P (2012) Epigenome-wide scans identify differentially methylated regions for age and age-related phenotypes in a healthy ageing population. PLoS Genet 8:e1002629

Ben-Avraham D, Muzumdar RH, Atzmon G (2012) Epigenetic genome-wide association methylation in aging and longevity. Epigenomics 4:503-509

Bendix L, Gade MM, Staun PW, Kimura M, Jeune B, Hjelmborg JV, Aviv A, Christensen K (2011) Leukocyte telomere length and 
physical ability among Danish twins age 70+. Mech Ageing Dev 132:568-572

Bergman A, Atzmon G, Ye K, MacCarthy T, Barzilai N (2007) Buffering mechanisms in aging: a systems approach toward uncovering the genetic component of aging. PLoS Comput Biol 3:e170

Bernstein AM, Willcox BJ, Tamaki H, Kunishima N, Suzuki M, Willcox DC, Yoo JS, Perls TT (2004) First autopsy study of an Okinawan centenarian: absence of many age-related diseases. J Gerontol A Biol Sci Med Sci 59:1195-1199

Bjornsson HT, Sigurdsson MI, Fallin MD, Irizarry RA, Aspelund T, Cui H, Yu W, Rongione MA, Ekstrom TJ, Harris TB, Launer LJ, Eiriksdottir G, Leppert MF, Sapienza C, Gudnason V, Feinberg AP (2008) Intra-individual change over time in DNA methylation with familial clustering. JAMA 299:2877-2883

Boyden SE, Kunkel LM (2010) High-density genomewide linkage analysis of exceptional human longevity identifies multiple novel loci. PLoS One 5:e12432

Brand FN, Kiely DK, Kannel WB, Myers RH (1992) Family patterns of coronary heart disease mortality: the Framingham longevity study. J Clin Epidemiol 45:169-174

Broer L, Demerath EW, Garcia ME, Homuth G, Kaplan RC, Lunetta KL, Tanaka T, Tranah GJ, Walter S, Arnold AM, Atzmon G, Harris TB, Hoffmann W, Karasik D, Kiel DP, Kocher T, Launer LJ, Lohman KK, Rotter JI, Tiemeier H, Uitterlinden AG, Wallaschofski H, Bandinelli S, Dorr M, Ferrucci L, Franceschini N, Gudnason V, Hofman A, Liu Y, Murabito JM, Newman AB, Oostra BA, Psaty BM, Smith AV, van Duijn CM (2012) Association of heat shock proteins with all-cause mortality. Age (Dordr) 35(4):1367-1376

Castri L, Melendez-Obando M, Villegas-Palma R, Barrantes R, Raventos H, Pereira R, Luiselli D, Pettener D, Madrigal L (2009) Mitochondrial polymorphisms are associated both with increased and decreased longevity. Hum Hered 67:147-153

Castro E, Edland SD, Lee L, Ogburn CE, Deeb SS, Brown G, Panduro A, Riestra R, Tilvis R, Louhija J, Penttinen R, Erkkola R, Wang L, Martin GM, Oshima J (2000) Polymorphisms at the Werner locus: II. 1074Leu/Phe, 1367Cys/Arg, longevity, and atherosclerosis. Am J Med Genet 95:374-380

Christensen K, Johnson TE, Vaupel JW (2006) The quest for genetic determinants of human longevity: challenges and insights. Nat Rev Genet 7:436-448

Conneely KN, Capell BC, Erdos MR, Sebastiani P, Solovieff N, Swift AJ, Baldwin CT, Budagov T, Barzilai N, Atzmon G, Puca AA, Perls TT, Geesaman BJ, Boehnke M, Collins FS (2012) Human longevity and common variations in the LMNA gene: a metaanalysis. Aging Cell 11:475-481

Cournil A, Kirkwood TB (2001) If you would live long, choose your parents well. Trends Genet 17:233-235

Courtenay MD, Gilbert JR, Jiang L, Cummings AC, Gallins PJ, Caywood L, Reinhart-Mercer L, Fuzzell D, Knebusch C, Laux R, McCauley JL, Jackson CE, Pericak-Vance MA, Haines JL, Scott WK (2012) Mitochondrial haplogroup X is associated with successful aging in the Amish. Hum Genet 131:201-208

De Benedictis G, Carotenuto L, Carrieri G, De Luca M, Falcone E, Rose G, Yashin AI, Bonafe M, Franceschi C (1998) Age-related changes of the $3^{\prime}$ APOB-VNTR genotype pool in ageing cohorts. Ann Hum Genet 62:115-122

De Benedictis G, Rose G, Carrieri G, De Luca M, Falcone E, Passarino G, Bonafe M, Monti D, Baggio G, Bertolini S, Mari D, Mattace R, Franceschi C (1999) Mitochondrial DNA inherited variants are associated with successful aging and longevity in humans. Faseb J 13:1532-1536

de Benedictis G, Carrieri G, Varcasia O, Bonafe M, Franceschi C (2000) Inherited variability of the mitochondrial genome and successful aging in humans. Ann N Y Acad Sci 908:208-218
Deelen J, Beekman M, Uh HW, Helmer Q, Kuningas M, Christiansen L, Kremer D, van der Breggen R, Suchiman HE, Lakenberg N, van den Akker EB, Passtoors WM, Tiemeier H, van Heemst D, de Craen AJ, Rivadeneira F, de Geus EJ, Perola M, van der Ouderaa FJ, Gunn DA, Boomsma DI, Uitterlinden AG, Christensen K, van Duijn CM, Heijmans BT, Houwing-Duistermaat JJ, Westendorp RG, Slagboom PE (2011a) Genome-wide association study identifies a single major locus contributing to survival into old age; the APOE locus revisited. Aging Cell 10:686-698

Deelen J, Uh HW, Monajemi R, van Heemst D, Thijssen PE, Bohringer S, van den Akker EB, de Craen AJ, Rivadeneira F, Uitterlinden AG, Westendorp RG, Goeman JJ, Slagboom PE, Houwing-Duistermaat JJ, Beekman M (2011b) Gene set analysis of GWAS data for human longevity highlights the relevance of the insulin/IGF-1 signaling and telomere maintenance pathways. Age (Dordr) 35(1):235-241

Deelen J, Uh HW, Monajemi R, van Heemst D, Thijssen PE, Bohringer S, van den Akker EB, de Craen AJ, Rivadeneira F, Uitterlinden AG, Westendorp RG, Goeman JJ, Slagboom PE, Houwing-Duistermaat JJ, Beekman M (2013) Gene set analysis of GWAS data for human longevity highlights the relevance of the insulin/IGF-1 signaling and telomere maintenance pathways. Age (Dordr) 35:235-249

Devlin B, Roeder K (1999) Genomic control for association studies. Biometrics 55:997-1004

Edwards DR, Gilbert JR, Jiang L, Gallins PJ, Caywood L, Creason M, Fuzzell D, Knebusch C, Jackson CE, Pericak-Vance MA, Haines JL, Scott WK (2011) Successful aging shows linkage to chromosomes 6, 7, and 14 in the Amish. Ann Hum Genet 75:516-528

Edwards DR, Gilbert JR, Hicks JE, Myers JL, Jiang L, Cummings AC, Guo S, Gallins PJ, Konidari I, Caywood L, Reinhart-Mercer L, Fuzzell D, Knebusch C, Laux R, Jackson CE, Pericak-Vance MA, Haines JL, Scott WK (2012) Linkage and association of successful aging to the 6q25 region in large Amish kindreds. Age (Dordr) 35(4): 1467-1477

ElSharawy A, Keller A, Flachsbart F, Wendschlag A, Jacobs G, Kefer N, Brefort T, Leidinger P, Backes C, Meese E, Schreiber S, Rosenstiel P, Franke A, Nebel A (2012) Genome-wide miRNA signatures of human longevity. Aging Cell 11:607-616

Evert J, Lawler E, Bogan H, Perls T (2003) Morbidity profiles of centenarians: survivors, delayers, and escapers. J Gerontol A Biol Sci Med Sci 58:232-237

Farrelly C (2012) 'Positive biology' as a new paradigm for the medical sciences. Focusing on people who live long, happy, healthy lives might hold the key to improving human well-being. EMBO Rep 13:186-188

Ferrario A, Villa F, Malovini A, Araniti F, Puca AA (2012) The application of genetics approaches to the study of exceptional longevity in humans: potential and limitations. Immun Ageing 9:7

Fries JF (1980) Aging, natural death, and the compression of morbidity. N Engl J Med 303:130-135

Garasto S, Rose G, Derango F, Berardelli M, Corsonello A, Feraco E, Mari V, Maletta R, Bruni A, Franceschi C, Carotenuto L, De Benedictis G (2003) The study of APOA1, APOC3 and APOA4 variability in healthy ageing people reveals another paradox in the oldest old subjects. Ann Hum Genet 67:54-62

Geesaman BJ, Benson E, Brewster SJ, Kunkel LM, Blanche H, Thomas G, Perls TT, Daly MJ, Puca AA (2003) Haplotype-based identification of a microsomal transfer protein marker associated with the human lifespan. Proc Natl Acad Sci USA 100: 14115-14120

Gentilini D, Mari D, Castaldi D, Remondini D, Ogliari G, Ostan R, Bucci L, Sirchia SM, Tabano S, Cavagnini F, Monti D, 
Franceschi C, Di Blasio AM, Vitale G (2012) Role of epigenetics in human aging and longevity: genome-wide DNA methylation profile in centenarians and centenarians' offspring. Age (Dordr)

Gerdes LU, Jeune B, Ranberg KA, Nybo H, Vaupel JW (2000) Estimation of apolipoprotein $\mathrm{E}$ genotype-specific relative mortality risks from the distribution of genotypes in centenarians and middle-aged men: apolipoprotein E gene is a "frailty gene," not a "longevity gene". Genet Epidemiol 19:202-210

Gombar S, Jung HJ, Dong F, Calder B, Atzmon G, Barzilai N, Tian XL, Pothof J, Hoeijmakers JH, Campisi J, Vijg J, Suh Y (2012) Comprehensive microRNA profiling in B-cells of human centenarians by massively parallel sequencing. BMC Genomics $13: 353$

Gravina S, Vijg J (2010) Epigenetic factors in aging and longevity. Pflugers Arch 459:247-258

Greer EL, Maures TJ, Ucar D, Hauswirth AG, Mancini E, Lim JP, Benayoun BA, Shi Y, Brunet A (2011) Transgenerational epigenetic inheritance of longevity in Caenorhabditis elegans. Nature 479:365-371

Gudmundsson H, Gudbjartsson DF, Frigge M, Gulcher JR, Stefansson K (2000) Inheritance of human longevity in Iceland. Eur J Hum Genet 8:743-749

Haddy N, De Bacquer D, Chemaly MM, Maurice M, Ehnholm C, Evans A, Sans S, Do Carmo Martins M, De Backer G, Siest G, Visvikis S (2002) The importance of plasma apolipoprotein E concentration in addition to its common polymorphism on interindividual variation in lipid levels: results from Apo Europe. Eur J Hum Genet 10:841-850

Halaschek-Wiener J, Vulto I, Fornika D, Collins J, Connors JM, Le ND, Lansdorp PM, Brooks-Wilson A (2008) Reduced telomere length variation in healthy oldest old. Mech Ageing Dev 129:638-641

Hannum G, Guinney J, Zhao L, Zhang L, Hughes G, Sadda S, Klotzle B, Bibikova M, Fan JB, Gao Y, Deconde R, Chen M, Rajapakse I, Friend S, Ideker T, Zhang K (2013) Genome-wide methylation profiles reveal quantitative views of human aging rates. Mol Cell 49:359-367

Hekimi S (2006) How genetic analysis tests theories of animal aging. Nat Genet 38:985-991

Herskind AM, McGue M, Holm NV, Sorensen TI, Harvald B, Vaupel JW (1996) The heritability of human longevity: a populationbased study of 2872 Danish twin pairs born 1870-1900. Hum Genet 97:319-323

Heyn H, Li N, Ferreira HJ, Moran S, Pisano DG, Gomez A, Diez J, Sanchez-Mut JV, Setien F, Carmona FJ, Puca AA, Sayols S, Pujana MA, Serra-Musach J, Iglesias-Platas I, Formiga F, Fernandez AF, Fraga MF, Heath SC, Valencia A, Gut IG, Wang J, Esteller M (2012) Distinct DNA methylomes of newborns and centenarians. Proc Natl Acad Sci USA 109:10522-10527

Hjelmborg I, Iachine A, Skytthe JW, Vaupel M, McGue M, Koskenvuo J, Kaprio NL, Pedersen K, Pedersen NL (2006) Genetic influence on human lifespan and longevity. Hum Genet 119:312-321

Hsin H, Kenyon C (1999) Signals from the reproductive system regulate the lifespan of C. elegans. Nature 399:362-366

Huebbe P, Nebel A, Siegert S, Moehring J, Boesch-Saadatmandi C, Most E, Pallauf J, Egert S, Muller MJ, Schreiber S, Nothlings U, Rimbach G (2011) APOE epsilon4 is associated with higher vitamin $\mathrm{D}$ levels in targeted replacement mice and humans. FASEB J 25:3262-3270

Huffman DM, Deelen J, Ye K, Bergman A, Slagboom EP, Barzilai N, Atzmon G (2012) Distinguishing between longevity and buffered-deleterious genotypes for exceptional human longevity: the case of the MTP gene. J Gerontol A Biol Sci Med Sci $67: 1153-1160$
Iwata N, Zhang J, Atzmon G, Leanza S, Cho J, Chomyn A, Burk RD, Barzilai N, Attardi G (2007) Aging-related occurrence in Ashkenazi Jews of leukocyte heteroplasmic mtDNA mutation adjacent to replication origin frequently remodeled in Italian centenarians. Mitochondrion 7:267-272

Jacobs KB, Yeager M, Zhou W, Wacholder S, Wang Z, RodriguezSantiago B, Hutchinson A, Deng X, Liu C, Horner MJ, Cullen M, Epstein CG, Burdett L, Dean MC, Chatterjee N, Sampson J, Chung CC, Kovaks J, Gapstur SM, Stevens VL, Teras LT, Gaudet MM, Albanes D, Weinstein SJ, Virtamo J, Taylor PR, Freedman ND, Abnet CC, Goldstein AM, Hu N, Yu K, Yuan JM, Liao L, Ding T, Qiao YL, Gao YT, Koh WP, Xiang YB, Tang ZZ, Fan JH, Aldrich MC, Amos C, Blot WJ, Bock CH, Gillanders EM, Harris CC, Haiman CA, Henderson BE, Kolonel LN, Le Marchand L, McNeill LH, Rybicki BA, Schwartz AG, Signorello LB, Spitz MR, Wiencke JK, Wrensch M, Wu X, Zanetti KA, Ziegler RG, Figueroa JD, Garcia-Closas M, Malats $\mathrm{N}$, Marenne G, Prokunina-Olsson L, Baris D, Schwenn M, Johnson A, Landi MT, Goldin L, Consonni D, Bertazzi PA, Rotunno M, Rajaraman P, Andersson U, Beane Freeman LE, Berg CD, Buring JE, Butler MA, Carreon T, Feychting M, Ahlbom A, Gaziano JM, Giles GG, Hallmans G, Hankinson SE, Hartge P, Henriksson R, Inskip PD, Johansen C, Landgren A, McKean-Cowdin R, Michaud DS, Melin BS, Peters U, Ruder AM, Sesso HD, Severi G, Shu XO, Visvanathan K et al (2012) Detectable clonal mosaicism and its relationship to aging and cancer. Nat Genet 44:651-658

Kerber RA, O’Brien E, Boucher KM, Smith KR, Cawthon RM (2012) A genome-wide study replicates linkage of 3p22-24 to extreme longevity in humans and identifies possible additional loci. PLoS One 7:e34746

Kim S, Bi X, Czarny-Ratajczak M, Dai J, Welsh DA, Myers L, Welsch MA, Cherry KE, Arnold J, Poon LW, Jazwinski SM (2012) Telomere maintenance genes SIRT1 and XRCC6 impact age-related decline in telomere length but only SIRT1 is associated with human longevity. Biogerontology 13:119-131

Kulminski AM, Culminskaya I (2011) Genomics of human health and aging. Age (Dordr) 35(1):455-469

Kuningas M, Slagboom PE, Westendorp RG, van Heemst D (2006) Impact of genetic variations in the WRN gene on age related pathologies and mortality. Mech Ageing Dev 127:307-313

Kuningas M, Estrada K, Hsu YH, Nandakumar K, Uitterlinden AG, Lunetta KL, van Duijn CM, Karasik D, Hofman A, Murabito J, Rivadeneira F, Kiel DP, Tiemeier H (2011a) Large common deletions associate with mortality at old age. Hum Mol Genet 20:4290-4296

Kuningas M, McQuillan R, Wilson JF, Hofman A, van Duijn CM, Uitterlinden AG, Tiemeier H (2011b) Runs of homozygosity do not influence survival to old age. PLoS One 6:e22580

Laurie CC, Laurie CA, Rice K, Doheny KF, Zelnick LR, McHugh CP, Ling H, Hetrick KN, Pugh EW, Amos C, Wei Q, Wang LE, Lee JE, Barnes KC, Hansel NN, Mathias R, Daley D, Beaty TH, Scott AF, Ruczinski I, Scharpf RB, Bierut LJ, Hartz SM, Landi MT, Freedman ND, Goldin LR, Ginsburg D, Li J, Desch KC, Strom SS, Blot WJ, Signorello LB, Ingles SA, Chanock SJ, Berndt SI, Le Marchand L, Henderson BE, Monroe KR, Heit JA, de Andrade M, Armasu SM, Regnier C, Lowe WL, Hayes MG, Marazita ML, Feingold E, Murray JC, Melbye M, Feenstra B, Kang JH, Wiggs JL, Jarvik GP, McDavid AN, Seshan VE, Mirel DB, Crenshaw A, Sharopova N, Wise A, Shen J, Crosslin DR, Levine DM, Zheng X, Udren JI, Bennett S, Nelson SC, Gogarten SM, Conomos MP, Heagerty P, Manolio T, Pasquale LR, Haiman CA, Caporaso N, Weir BS (2012) Detectable clonal mosaicism from birth to old age and its relationship to cancer. Nat Genet 44:642-650 
Lunetta KL, D’Agostino RB Sr, Karasik D, Benjamin EJ, Guo CY, Govindaraju R, Kiel DP, Kelly-Hayes M, Massaro JM, Pencina MJ, Seshadri S, Murabito JM (2007) Genetic correlates of longevity and selected age-related phenotypes: a genome-wide association study in the Framingham Study. BMC Med Genet 8(Suppl 1):S13

Malovini A, Illario M, Iaccarino G, Villa F, Ferrario A, Roncarati R, Anselmi CV, Novelli V, Cipolletta E, Leggiero E, Orro A, Rusciano MR, Milanesi L, Maione AS, Condorelli G, Bellazzi R, Puca AA (2011) Association study on long-living individuals from Southern Italy identifies rs10491334 in the CAMKIV gene that regulates survival proteins. Rejuvenation Res 14: 283-291

Manolio TA (2007) Study designs to enhance identification of genetic factors in healthy aging. Nutr Rev 65:S228-S233

Mooijaart SP, van Heemst D, Noordam R, Rozing MP, Wijsman CA, de Craen AJ, Westendorp RG, Beekman M, Slagboom PE (2011) Polymorphisms associated with type 2 diabetes in familial longevity: the Leiden longevity study. Aging (Albany NY) 3:55-62

Morris BJ, Donlon TA, He Q, Grove JS, Masaki KH, Elliott A, Willcox DC, Willcox BJ (2013) Association analyses of insulin signaling pathway gene polymorphisms with healthy aging and longevity in Americans of Japanese ancestry. J Gerontol A Biol Sci Med Sci

Murabito JM, Yuan R, Lunetta KL (2012) The search for longevity and healthy aging genes: insights from epidemiological studies and samples of long-lived individuals. J Gerontol A Biol Sci Med Sci 67:470-479

Nebel A, Schreiber S (2005) Allelic variation and human longevity. Sci Aging Knowledge Environ 2005(29):pe23

Nebel A, Croucher PJ, Stiegeler R, Nikolaus S, Krawczak M, Schreiber S (2005) No association between microsomal triglyceride transfer protein (MTP) haplotype and longevity in humans. Proc Natl Acad Sci USA 102:7906-7909

Nebel A, Flachsbart F, Till A, Caliebe A, Blanche H, Arlt A, Hasler R, Jacobs G, Kleindorp R, Franke A, Shen B, Nikolaus S, Krawczak M, Rosenstiel P, Schreiber S (2009) A functional EXO1 promoter variant is associated with prolonged life expectancy in centenarians. Mech Ageing Dev 130:691-699

Nebel A, Kleindorp R, Caliebe A, Nothnagel M, Blanche H, Junge O, Wittig M, Ellinghaus D, Flachsbart F, Wichmann HE, Meitinger T, Nikolaus S, Franke A, Krawczak M, Lathrop M, Schreiber S (2011) A genome-wide association study confirms APOE as the major gene influencing survival in long-lived individuals. Mech Ageing Dev 132:324-330

Newman AB, Murabito JM (2013) The epidemiology of longevity and exceptional survival. Epidemiol Rev 35(1):181-197

Newman AB, Walter S, Lunetta KL, Garcia ME, Slagboom PE, Christensen K, Arnold AM, Aspelund T, Aulchenko YS, Benjamin EJ, Christiansen L, D'Agostino RB Sr, Fitzpatrick AL, Franceschini N, Glazer NL, Gudnason V, Hofman A, Kaplan R, Karasik D, Kelly-Hayes M, Kiel DP, Launer LJ, Marciante KD, Massaro JM, Miljkovic I, Nalls MA, Hernandez D, Psaty BM, Rivadeneira F, Rotter J, Seshadri S, Smith AV, Taylor KD, Tiemeier H, Uh HW, Uitterlinden AG, Vaupel JW, Walston J, Westendorp RG, Harris TB, Lumley T, van Duijn CM, Murabito JM (2010) A meta-analysis of four genome-wide association studies of survival to age 90 years or older: the cohorts for heart and aging research in genomic epidemiology consortium. J Gerontol A Biol Sci Med Sci 65:478-487

Newman AB, Glynn NW, Taylor CA, Sebastiani P, Perls TT, Mayeux R, Christensen K, Zmuda JM, Barral S, Lee JH, Simonsick EM, Walston JD, Yashin AI, Hadley E (2011) Health and function of participants in the Long Life Family Study: a comparison with other cohorts. Aging (Albany NY) 3:63-76
Niemi AK, Hervonen A, Hurme M, Karhunen PJ, Jylha M, Majamaa K (2003) Mitochondrial DNA polymorphisms associated with longevity in a Finnish population. Hum Genet 112:29-33

Njajou OT, Hsueh WC, Blackburn EH, Newman AB, Wu SH, Li R, Simonsick EM, Harris TM, Cummings SR, Cawthon RM (2009) Association between telomere length, specific causes of death, and years of healthy life in health, aging, and body composition, a population-based cohort study. J Gerontol A Biol Sci Med Sci 64:860-864

Paaby AB, Schmidt PS (2009) Dissecting the genetics of longevity in Drosophila melanogaster. Fly (Austin) 3:29-38

Passtoors WM, Beekman M, Deelen J, van der Breggen R, Maier AB, Guigas B, Derhovanessian E, van Heemst D, de Craen AJ, Gunn DA, Pawelec G, Slagboom PE (2013) Gene expression analysis of mTOR pathway: association with human longevity. Aging Cell 12:24-31

Perls T, Shea-Drinkwater M, Bowen-Flynn J, Ridge SB, Kang S, Joyce E, Daly M, Brewster SJ, Kunkel L, Puca AA (2000) Exceptional familial clustering for extreme longevity in humans. J Am Geriatr Soc 48:1483-1485

Perls TT, Wilmoth J, Levenson R, Drinkwater M, Cohen M, Bogan H, Joyce E, Brewster S, Kunkel L, Puca A (2002) Life-long sustained mortality advantage of siblings of centenarians. Proc Natl Acad Sci USA 99:8442-8447

Polito L, Kehoe PG, Forloni G, Albani D (2010) The molecular genetics of sirtuins: association with human longevity and agerelated diseases. Int J Mol Epidemiol Genet 1:214-225

Price AL, Patterson NJ, Plenge RM, Weinblatt ME, Shadick NA, Reich D (2006) Principal components analysis corrects for stratification in genome-wide association studies. Nat Genet 38:904-909

Puca AA, Daly MJ, Brewster SJ, Matise TC, Barrett J, SheaDrinkwater M, Kang S, Joyce E, Nicoli J, Benson E, Kunkel LM, Perls T (2001) A genome-wide scan for linkage to human exceptional longevity identifies a locus on chromosome 4. Proc Natl Acad Sci USA 98:10505-10508

Rajpathak SN, Liu Y, Ben-David O, Reddy S, Atzmon G, Crandall J, Barzilai N (2011) Lifestyle factors of people with exceptional longevity. J Am Geriatr Soc 59:1509-1512

Reed T, Dick DM (2003) Heritability and validity of healthy physical aging (wellness) in elderly male twins. Twin Res 6:227-234

Reed T, Dick DM, Uniacke SK, Foroud T, Nichols WC (2004) Genome-wide scan for a healthy aging phenotype provides support for a locus near D4S1564 promoting healthy aging. J Gerontol A Biol Sci Med Sci 59:227-232

Ren WH, Li XH, Zhang HG, Deng FM, Liao WQ, Pang Y, Liu YH, Qiu MJ, Zhang GY, Zhang YG (2008) Mitochondrial DNA haplogroups in a Chinese Uygur population and their potential association with longevity. Clin Exp Pharmacol Physiol 35: 1477-1481

Risques RA, Arbeev KG, Yashin AI, Ukraintseva SV, Martin GM, Rabinovitch PS, Oshima J (2010) Leukocyte telomere length is associated with disability in older u.s Population. J Am Geriatr Soc 58:1289-1298

Robine JM, Allard M (1998) The oldest human. Science 279: 1834-1835

Rose G, Dato S, Altomare K, Bellizzi D, Garasto S, Greco V, Passarino G, Feraco E, Mari V, Barbi C, BonaFe M, Franceschi C, Tan Q, Boiko S, Yashin AI, De Benedictis G (2003) Variability of the SIRT3 gene, human silent information regulator Sir2 homologue, and survivorship in the elderly. Exp Gerontol 38:1065-1070

Ross OA, McCormack R, Curran MD, Duguid RA, Barnett YA, Rea IM, Middleton D (2001) Mitochondrial DNA polymorphism: its role in longevity of the Irish population. Exp Gerontol 36:1161-1178 
Rutherford SL, Lindquist S (1998) Hsp90 as a capacitor for morphological evolution. Nature 396:336-342

Santoro A, Salvioli S, Raule N, Capri M, Sevini F, Valensin S, Monti D, Bellizzi D, Passarino G, Rose G, De Benedictis G, Franceschi C (2006) Mitochondrial DNA involvement in human longevity. Biochim Biophys Acta 1757:1388-1399

Sarup P, Sorensen P, Loeschcke V (2011) Flies selected for longevity retain a young gene expression profile. Age (Dordr) 33:69-80

Sebastiani P, Perls TT (2012) The genetics of extreme longevity: lessons from the new England centenarian study. Front Genet 3:277

Sebastiani P, Riva A, Montano M, Pham P, Torkamani A, Scherba E, Benson G, Milton JN, Baldwin CT, Andersen S, Schork NJ, Steinberg MH, Perls TT (2011) Whole genome sequences of a male and female supercentenarian, ages greater than 114 years. Front Genet 2:90

Sebastiani P, Solovieff N, Dewan AT, Walsh KM, Puca A, Hartley SW, Melista E, Andersen S, Dworkis DA, Wilk JB, Myers RH, Steinberg MH, Montano M, Baldwin CT, Hoh J, Perls TT (2012) Genetic signatures of exceptional longevity in humans. PLoS One 7:e29848

Seripa D, Franceschi M, Matera MG, Panza F, Kehoe PG, Gravina C, Orsitto G, Solfrizzi V, Di Minno G, Dallapiccola B, Pilotto A (2006) Sex differences in the association of apolipoprotein $\mathrm{E}$ and angiotensin-converting enzyme gene polymorphisms with healthy aging and longevity: a population-based study from Southern Italy. J Gerontol A Biol Sci Med Sci 61:918-923

Shlush LI, Atzmon G, Weisshof R, Behar D, Yudkovsky G, Barzilai N, Skorecki K (2008) Ashkenazi Jewish centenarians do not demonstrate enrichment in mitochondrial haplogroup. J. PLoS One 3:e3425

Soerensen M, Thinggaard M, Nygaard M, Dato S, Tan Q, Hjelmborg J, Andersen-Ranberg K, Stevnsner T, Bohr VA, Kimura M, Aviv A, Christensen K, Christiansen L (2012) Genetic variation in TERT and TERC and human leukocyte telomere length and longevity: a cross-sectional and longitudinal analysis. Aging Cell 11:223-227

Sondheimer N, Glatz CE, Tirone JE, Deardorff MA, Krieger AM, Hakonarson H (2011) Neutral mitochondrial heteroplasmy and the influence of aging. Hum Mol Genet 20:1653-1659

Talens RP, Christensen K, Putter H, Willemsen G, Christiansen L, Kremer D, Suchiman HE, Slagboom PE, Boomsma DI, Heijmans BT (2012) Epigenetic variation during the adult lifespan: cross-sectional and longitudinal data on monozygotic twin pairs. Aging Cell 11:694-703

Tanaka M, Gong JS, Zhang J, Yoneda M, Yagi K (1998) Mitochondrial genotype associated with longevity. Lancet 351:185-186
Terracciano A, Lockenhoff CE, Zonderman AB, Ferrucci L, Costa PT Jr (2008) Personality predictors of longevity: activity, emotional stability, and conscientiousness. Psychosom Med 70:621-627

Terry DF, Wilcox MA, McCormick MA, Pennington JY, Schoenhofen EA, Andersen SL, Perls TT (2004) Lower all-cause, cardiovascular, and cancer mortality in centenarians' offspring. J Am Geriatr Soc 52:2074-2076

Tissenbaum HA, Guarente L (2002) Model organisms as a guide to mammalian aging. Dev Cell 2:9-19

Tranah GJ (2011) Mitochondrial-nuclear epistasis: implications for human aging and longevity. Ageing Res Rev 10:238-252

Walter S, Atzmon G, Demerath EW, Garcia ME, Kaplan RC, Kumari M, Lunetta KL, Milaneschi Y, Tanaka T, Tranah GJ, Volker U, Yu L, Arnold A, Benjamin EJ, Biffar R, Buchman AS, Boerwinkle E, Couper D, De Jager PL, Evans DA, Harris TB, Hoffmann W, Hofman A, Karasik D, Kiel DP, Kocher T, Kuningas M, Launer LJ, Lohman KK, Lutsey PL, Mackenbach J, Marciante K, Psaty BM, Reiman EM, Rotter JI, Seshadri S, Shardell MD, Smith AV, van Duijn C, Walston J, Zillikens MC, Bandinelli S, Baumeister SE, Bennett DA, Ferrucci L, Gudnason V, Kivimaki M, Liu Y, Murabito JM, Newman AB, Tiemeier H, Franceschini N (2011) A genome-wide association study of aging. Neurobiol Aging 32(2109):e15-e28

Westendorp RG, van Heemst D, Rozing MP, Frolich M, Mooijaart SP, Blauw GJ, Beekman M, Heijmans BT, de Craen AJ, Slagboom PE (2009) Nonagenarian siblings and their offspring display lower risk of mortality and morbidity than sporadic nonagenarians: the Leiden longevity study. J Am Geriatr Soc 57:1634-1637

Wheeler HE, Kim SK (2011) Genetics and genomics of human ageing. Philos Trans R Soc Lond B Biol Sci 366:43-50

Willcox BJ, Willcox DC, He Q, Curb JD, Suzuki M (2006) Siblings of Okinawan centenarians share lifelong mortality advantages. J Gerontol A Biol Sci Med Sci 61:345-354

Yashin AI, Wu D, Arbeev KG, Ukraintseva SV (2010) Joint influence of small-effect genetic variants on human longevity. Aging (Albany NY) 2:612-620

Yuan R, Peters LL, Paigen B (2011) Mice as a mammalian model for research on the genetics of aging. ILAR J 52:4-15

Zhang J, Asin-Cayuela J, Fish J, Michikawa Y, Bonafe M, Olivieri F, Passarino G, De Benedictis G, Franceschi C, Attardi G (2003) Strikingly higher frequency in centenarians and twins of mtDNA mutation causing remodeling of replication origin in leukocytes. Proc Natl Acad Sci USA 100:1116-1121

Zhu H, Belcher M, van der Harst P (2011) Healthy aging and disease: role for telomere biology? Clin Sci (Lond) 120:427-440 